\title{
Beyond Nature and Subjectivity -The Issues of Space in Nathaniel Hawthorne' s The Scarlet Letter
}

\author{
Xiaohan $\mathrm{Mei}^{1}$ \\ ${ }^{1}$ M.A. in Fudan University, China \\ Correspondence: Xiaohan Mei, Department of Comparative Literature and World Literature, Fudan University, China.
}

Received: May 10, 2019

Accepted: June 10, $2019 \quad$ Available online: June 24, 2019

doi:10.11114/ijsss.v7i4.4337

URL: https://doi.org/10.11114/ijsss.v7i4.4337

\begin{abstract}
In Nathaniel Hawthorne' s literary creation, the usages of space are usually highlighted by Hawthorne' s arrangement of the settings, scenes and social background. In The Scarlet Letter, according to the spatial turn in $20^{\text {th }}$ spatial theories - especially the spatial theory of Lefebvre, Nathaniel Hawthorne constructed three spaces in this romance novel: the material space, spiritual space and social space. These three kinds of space are not simply juxtaposed, but are intervening, intermingling, superimposing each other, and sometimes even contradicting each other. It is through the construction of space that Hawthorne combines serious moral content with excellent artistic expressions, giving The Scarlet Letter its powerful vitality and enduring charm. It is also through the construction of space that the theme and meaning of the novel about the human spiritual ecological crisis is better manifested, and shows Hawthorne's contemplation and transcendence of the real world. In the process of interpreting the space construction of The Scarlet Letter, readers can appreciate the narrative techniques and artistic effects of the text, and then examine the social reality that the novel should express.
\end{abstract}

Keywords: The Scarlet Letter, Spatial Theory, Nathaniel Hawthorne

\section{Introduction: Hawthorne and the Problem of Space}

Time and space are the basic forms of all existence, and two important dimensions for human perception and understanding of the world. Similarly, the romance novel, though based on the "neutral territory, somewhere between the real world and fairy-land," (Hawthorne, 1983: p. 149) owns both the dimension of time and dimension of space. A romance novel is an art of time, not only because it requires physical time to organize narratives, but it also needs to monitor the fluent of the society and adapt itself to these changes, in order to accommodate with the social reality. On the other hand, the romance novel should also be taken as a kind of spatial art according to the metaphor of "territory" used by Hawthorne himself. It seems impossible for any fictional narrative to completely abolish the space and to seek the existence of pure time. The space at least provides the narrative with the realm, support or paving of the plot development, and is closely related to the social background of the romance writers. ${ }^{1}$ The philosophical trend of spatial thought in the 20th century influenced the critics' aesthetic tendencies of the literary world, and the importance of space became increasingly prominent in the $20^{\text {th }}$ century literary criticism. After the $1970 \mathrm{~s}$, the flourish of the spatial theory realized the spatial turn of critical theories marked by social constructionism under the interpretation and guidance of several theorists such as Henri Lefebvre, Michel Foucault, Edward W. Soja, David Harvey, Yi-Fu Tuan and Fredric Jameson.

The development of the spatial theory arouses the rationality of adjusting the spatial theory into the literary critics. The space in the literary world, as the outcome of the fabrication, is even more complicated than the real world, since the literary world mingles writers' experience of the literary world and the real world. Michel Foucault' s statements in Power/Knowledge (1980) provides us with the potential of utilizing the spatial theory into the literary world, since he arouses the junction between the narrators or characters and their spatial background in the literary world, for the reason

\footnotetext{
${ }^{1}$ Hawthorne's use of the time and its relationship with the time is also closely linked to the change of the concept of time and space, and their real effects in $19^{\text {th }}$ century American society, cf. Halliday, Sam (2007). Science and technology in the age of Hawthorne, Melville, Twain, and James : thinking and writing electricity. New York: Palgrave Macmillan, chap. 1 .
} 
that there are always a serious of events in the literary works happened in the space set by the novel itself, and these events will harmonize the whole literary world in the book. The relationship between the spatial setting and the coherence of the literary world are always linked to each other and from a united entity. And Lefebvre, in his work The Production of Space (1974), opposed traditional social theory to simply regard space as a container or platform for the evolution of social relations and vice versa, to point out that it is an important part of social relations. Space is produced in historical development, restructure and transform as history evolves. He believes that the space we pay attention to is three kinds of material, spiritual and social. Before the emergence of unified critical theory, these three spaces exist in the form of isolated and scattered knowledge. The spatial knowledge should link the materialized space, the spiritual space and the social space, so that a unitive space can be spared into various spaces. In addition, this work brought about a fundamental change in the tradition of eliminating space through time. He corrected the simple and wrong view of traditional theory on space, including the mixture between the natural space and the artificial space, the heterogeneity of the space, and the differences between the abstract space and the social space. Since Lefebvre introduced many different factors, including politics, economics, the urban culture and geography into the spatial study, he created a well-rounded ideological system about the track of the space and its meaning in contemporary society. He believed that space is not only a static container or platform for the evolution of social relations, but also a dynamic practice process, and it also superimposes the triple dialectic of society, history and space. He divided the spatial structure into three elements: space practice, spatial reproduction and reproduction space, that is, the three aspects of the actual conception and perception of space. He particularly emphasized the social attributes of space, and believes that space is generated, but at the same time it has some inherent connection to social and human behavior. In his view, "to underestimate, ignore and diminish space amounts to the overestimation of texts, written matter, and writing systems, along with the readable and the visible, to the point of assigning to these a monopoly on intelligibility." (Lefebvre, 1991: p.62). The spatial turn in contemporary western academic thoughts triggered by him, and then Soja, also entered the field of literary studies from different angles, which led to the spatial turn of current narrative theory research. Space issues have become one of the focuses of current narrative theory. Since then, more scholars have begun to pay attention to spatial theory.

The ignorance of the spatial problems in Hawthorne's works will lead to the simplification of his work. Space can not only be related to the nature of the physical entity or the experiential recognition of the real world, but more importantly, it also produces metaphysical ideology such as social relations, power operations, and even human thoughts that people can't see or touch but fill the corners of space. On the other hand, space is the key to the transformation of these conceptual forms into reality. ${ }^{2}$ Therefore, space and ideology are inseparable and organically combined with each other. Before the formation and development of contemporary spatial theory, Nathaniel Hawthorne has already consciously incorporated spatial narrative into literary creation, including "The Hollow of the Three Hills" (1830), "The May-Pole of Merry Mount " (1836), "Legends of the Province House" (1838-1839), "Peter Goldthwaite's Treasure" (1838), "The Hall of Fantasy" (1843), and he also expresses his opinion about the relationship between the writer and the space he lives in "The Old Manse" (1846). ${ }^{3}$ These short romances not only provide "the provisional space in which to tackle subjects that challenge representation, such as delusion, self-exile, and mental illness" (Fernie, 2011: p.186), but also shows that his heterogeneous thoughts of space has run through his creating career, and also represented in The Scarlet Letter. In this work, he constructed three relatively independent spaces, including material space, spiritual space and social space that blended with each other and penetrated each other. Through the construction of space, Hawthorne showed superb narrative skills and extraordinary artistic effects. The space in this romance not only provided sites for the whole story, but also points to the real social context of the story. Therefore, the issues of space contained in this work go far beyond the mere background or arena of the story, but are also closely connected with the personal fate and their understanding of the real world. The concept of space in The Scarlet Letter transcends the traditional simplex images of the space in fictional works, including geographic space, housing space and city space, and provides us a well-rounded system of space among the whole novel.

\section{The Production and the Epistemology of Space in the Novel}

In "Regional Geography of Thomas Hardy" (1948), H.C. Darby thinks that fiction, as a literary form, must be born with geographical traits. The world of fiction is composed of orientation, venue, scene boundary, perspective and field of vision, which can be tenuously linked to the real world. The characters in the novel are in various places and space, and the narrator and the reader are also reading along with the shift of the places and space. Therefore, during the reading of novels, though there exists a huge gap both in the dimension of time and space between the readers and writers, readers may still "cannot fail to be struck time and again by the fidelity of this or that scene" (Darby,1948: p.443) for the reason

\footnotetext{
${ }^{2}$ Cf. Damion Searls's Ph.D thesis, Fictional Space from The Spectator to Hawthorne. University of California, Berkeley, 2001, in which he discusses Hawthorne's transformation of the real space and the fictional space.

${ }^{3}$ Cf. Olsen, Taimi Anne (2000). Transcending Space: Architectural Places in Works by Henry David Thoreau, E.E. Cummings, and John Barth. Plainsboro: Associated University Presses: 31-32
} 
that the geography in the novel will keep summoning the inner experience from the readers, and then create a coherence link between the space in the real world and in the fictional world. In The Scarlet Letter, Hawthorne makes readers placed in specific material spaces by using spatial art techniques, novel characters, narrators. The core of this material space is the prison table presented by the novel. In the process of presenting this space, Hawthorne uses the stage space skills freely, when he tries to describe the scene from the perspective of the audience on the auditorium. The novel provides the space as the background stage in two dimensions: firstly, the reader of the novel can take Boston as the basic stage of the novel; in the meantime, Hawthorne frequently uses the relation between the audience and the actors on the stage. Those characters in the novel seem to be the focus, background and characters on the theater stage. All the acts and dialogues are like theater scenes, presented by Hawthorne in front of audiences and readers.

The very certain materialized space in the novel should be scrutinized carefully, since we cannot intermingle the places in the real world with the man-made places in the novel. To be more specific, the production of space has already been set at the beginning of the novel, even though the materialized space provides the stage of the story, it cannot be seen as the fixed space, but should be taken as an ever-changed entity. In "The Custom-House" as the introductory, Hawthorne (1983) shows us his view about the Boston according to the depiction of the house "ornamented with a portico of half a dozen wooden pillars, supporting a balcony, beneath which a flight of wide granite steps descends towards the street" (p. 122) with a scared hawk. The decoration of the house, the first depiction of the space in the whole work, represents the keynote of the whole social space in Boston, the traditional and absolute fidelity to the American spirit and the rigid rules. However, even though the mainstream of the space in the work has already founded in "The Custom-House", the splices of space usually appear step by step throughout the whole, which means that readers need to explore various representations of the space in the work, and then piece them together to get their own view about the images of the space, just like those characters in the work. Hence, the production of the space and the cognition of the space happens simultaneously in the novel, make these two activities become the homogeneous process. Therefore, the space in the novel turns into a kind of "logico-epistemological space", including "the space of social practice, the space occupied by sensory phenomena, including products of the imagination such as projects and projections, symbols and utopias." (Lefebvre, 1991: p.11-12) This statement provides us with a unique view of the space, which I call the spatial dualism, of Lefebvre himself, which means that the ideological space produced by human recognition grew upon the materialized space. This is the reason why "whatever Utopia of human virtue and happiness they might originally project, have invariably recognized it among their earliest practical necessities to allot a portion of the virgin soil as a cemetery, and another portion as the site of a prison," (Hawthorne, 1983: p. 158) because the construction of a space is also the realization of their inner idea and their epistemology points. ${ }^{4}$ Therefore, we can understand the gossiping from those crowds about Hester Prynne, since they link their idea of individual to the certain space she belongs to, instead of her real images.

Therefore, the production of space in The Scarlet Letter cannot be a pure ideology process, but also a perception of the real space, such as the Custom-House in the introduction of the work and the prison in chap. 1, which can link people's cognition with the real world. In the chap.12, after Dimmesdale goes back to the platform once used by Hester, Hawthorne depicts a scene mixed up with the reality and the illusions: "the clergyman...beheld the appearance of the old magistrate himself, with a lamp in his hand, a white nightcap on his head, and a long white gown enveloping his figure. He looked like a ghost, evoked unseasonably from the grave," (p. 246) whose attention is attracted by the dim light set up with " a garden-fence" and "a latticed window-pane, and there a pump, with its full trough of water, and here, again, an arched door of oak, with an iron knocker, and a rough log for the door-step." (p. 247) Though the space where Dimmesdale stays in, both the platform and the avenue before him, are depicted like real entities. However, the are nothing more than the imagination in Dimmesdale's mind. Meanwhile, if we pay attention to the "door of oak", we may recall the prison in the chap. 1. Hence, Hawthorne gives detailed descriptions of the scene of this torture platform and the balcony, because many key scenes in the novel occurred and will occur in this space. Therefore, it will consistently summon characters' and readers' memory of the past according to the Recurring of a certain space. It is self-evident that the importance and necessity of leaving this scene clear in the reader's mind. Because she was standing on the platform to show her the two crimes of her adultery, The Scarlet Letter and Pearl, Hester became the focus of attention. On the way to the torture platform and around the torture platform, the townspeople watched her; the governor on the balcony of the conference room and several of his representatives, a judge, a general and a pastor in the city looked down at her; The special husband, Roger Chillingworth, appear on the edge of the crowd as a stranger, staring at her and signaling her not to recognize him in public. Pastor Wilson, Governor Bellingham, and Pastor Dimmesdale spoke one after another with Hester, forcing her to name the child's father. In this stage space set by Hawthorne, Hester is obviously a still life, and all actions take place around her.

\footnotetext{
${ }^{4}$ About the space of prisons, cf. Foucault, Michel. Trans. Alan Sheridan (1995). Discipline \& Punish: The Birth of the Prison. New York: Vintage Books, part4.
} 
However, there is no doubt that Hawthorne owns the clear concept between the space in the real world and the space in individuals' idea, and usually provides us the clear bound between the real space and the imaginary space. In the scene discussed above, when Dimmesdale slams into the top of the platform and continues his wandering in the night, he meets Hester and Pearl, who have just returned from Philippe Winthrop's bed. Then they climb up to the platform, then forms a certain scene on the platform:

She (Hester) silently ascended the steps, and stood on the platform, holding little Pearl by the hand. The minister felt for the child's other hand, and took it. The moment that he did so, there came what seemed a tumultuous rush of new life, other life than his own, pouring like a torrent into his heart, and hurrying through all his veins, as if the mother and the child were communicating their vital warmth to his halftorpid system. The three formed an electric chain. ( Hawthorne, 1983: p. 250)

This can be taken as the result of Hawthorne's deliberate styling, since shortly after, "a light gleamed far and wide over all the muffled sky" (Hawthorne, 1983: p. 250) accompanied with Dimmesdale's "looking upward to the zenith beheld there the appearance of an immense letter,the letter A." (Hawthorne, 1983: p. 252) Hence, Hawthorne provides with a special mark of the rift between the imaginary space and the real space, the "object space and space of "the world" as a continuous, uniform view" (Dolis, 1993: p. 17) which we have already seen in the "Night Sketches" (1838). When these characters are standing on the real space, the platform, their mind are still enchanted by the lightening and the letter in the sky. Then at this moment, the four main characters are all set in this important scene mixed with the real material space and the space in their mind. They are placed face to face in a dramatic situation, forming a dramatic picture, thus portraying rich stage space and strong stage effects. At the end of the story, also in this particular material space, when the parade walked over the platform, Dimmesdale called Hester and Pearl. At this time, Dimmesdale needed Hester to give psychological and physical support to help him retire on the platform. Even more dramatic is that Chillingworth tried to stop Dimmesdale from repenting and prevented Hester from approaching Dimmesdale. Chillingworth instinctively follows them because he was also one of the actors in this sinful and painful drama. After that, Dimmesdale solemnly bids farewell to the death on the torture platform. In this way, Hawthorne deliberately makes these closely related characters appear together, interpreting different plots of different stages of the story in the same material space, and finally pushing the story to a climax.

To make a phased conclusion, in terms of using the construction and the Epistemology of both material space and imaginary space, Hawthorne creates many stable spaces, including the prison and the platform, with geographical attributions and stability relate to time, in The Scarlet letter. According to these heterogeneous spaces, Hawthorne successfully manifests the complex social forms and the social contexts of Salem, the complicated relationship between the recognition of people and the space they live in, and the blurry bound between the imaginary space and the material space. However, the material space presented by The Scarlet Letter is not only a spatial reference to a certain space in the real world, but also includes other specific spatial entities, such as Boston, Hester's hut, the Governance Hall, Chillingworth's Laboratory, and Forests. ${ }^{5}$ The main material space of the representative activities of the space center on the torture platform, which specifically shows the conflict of interpersonal relationships, constitutes the scene of the plot. But in the meanwhile, material spaces also prevail through the whole story and play their unique roles in the different phases, then promotes the development of the story and creates a dramatic scene that plays a direct role in determining the character's fate and the state of the plot.

\section{Space and Mind: The Junction of Individuals and Place}

We have already built a link between the materialized world with people's epistemology of the space in The Scarlet Letter, which represents a relation between people's recognition of the space and the real space. However, the relationship between the human mind and the space is still remained to be resolved. Since "space as fundamentally bound up with social reality. It follows that space 'in itself' can never serve as an epistemological starting position. Space does not exist 'in itself'; it is produced." (Schmid,2008: p.28) Because human's rationale cannot signify the production of the space, the human mind should be taken into consideration of the production of the space. Soja (1996) once analyzed the concept of spatial epistemologies, which: "are immediately distinguishable by their explanatory concentration on conceived rather than perceived space and their implicit assumption that spatial knowledge is primarily produced though discursively devised representations of space, through the spatial workings of the mind." (p.78-79) Meanwhile, the analysizing of the space also experienced a turning "from ontology to epistemology, theory building, empirical analysis, and social practice." (p.71) He believes that "the production of knowledge is mainly accomplished through the spatial reconstruction of discourse construction, so attention is focused on the space of conception rather than the space of perception." (Soja,1996: p.79) Therefore, when put under a certain material space, as we discussed in the paragraph above, individuals

\footnotetext{
5 The forest seems to be the only natural space in the list above, however, since the events happened in the forest, from chap. 16 to chap. 19, is closely linked to the inner world of characters, we can not merely take it as a natural site or a stage of the story.
} 
will from the certain knowledge about the space they live in, and undoubtedly from a kind of connection with the local space, both physically and psychologically. The meaning of the "spatial turn", thus, is far from realizing "a reworking of the very notion and significance of spatiality to offer a perspective in which space is every bit as important as time in the unfolding of human affairs" (Warf \&Arias,2009: p.1) in the geography study area, but will also help individuals realize that the spatial world is a "hypothetical world" which should be taken as "a creative figment of someone's geographical imagination, a synthetic mapping that stimulated a general understanding of an extraordinary variety of empirical real world conditions," (Soja,2009: p.14-15) which leaves a great area for the imagination of human mind. In the description of The Scarlet Letter, in addition to describing the character activities, the descriptions of the psychological activities are also closely linked to the spatial world. There is no doubt that the human spirit cannot be split from the space in the world. Based on Yi-Fu Tuan's (1977) investigation of the historical development of the relationship between the subject and the space in the Cristian world, "astral time and space also affect the produce of the earth and the timing of human labor. But the micro-macro cosmic schema does not impose any clear spatial organization on the earth's surface." (p. 90) Hence, we cannot easily separate people's inner world from the outside world they live in with a clear bound, but on the other hand, people's recognition of the space in the real world will largely affected by this kind of vagueness.

Certainly, what Foucault (1986) said in "Of Other Spaces" builds a clear link between the epistemology and the change of the space in the world. The concept of "site", a certain situation of human "in a given situation," (p.23) can help us understand the relationship between human and the materialized space, what we have discussed above, as a inter-wind relationship between people's inner world, the spiritual, and the outside world, the materialized space, or the solid social background. In addition to the material space, Hawthorne also demonstrated the spiritual space that has been derived from the needs of life for the main characters, namely the spiritual world of Hester, Dimmesdale and Chillingworth. These main characters not only live in the specific material space depicted in the novel, but also live in the spiritual space that other people do not know and belong to them. For the first time, Hester had an awe-inspiring attitude toward the appearance of the prison, but her heart was heavy and full of pain. Because of the inability to get rid of the outside world, Hester had to seek help from her inner world - the memory of her and the world she imagined. Relying on the pillars of thought and facing the indignation of the people for her adultery crimes, Hester placed himself in the spiritual world and could endure the humiliation in front of him. Throughout the story, Hester generally remained silent, in the material space of the town, endure the bullying of the Puritan up to the adults to the children. The scarlet letter on her chest and the painful accusations of accepting the townspeople are to redeem her adultery crime. She is not really upset about her sin. She lives in isolation, thinking about and examining the progress of women in the world. She is fearless because she is at the bottom of the social ladder. Although Pearl was a living witness to her sin, she decorated her with the most dazzling colors to express her deep inner struggle. When Hester enjoyed the long-lost freedom in the forest, she relaxed to some extent. When she took down The Scarlet Letter and loosened the long black hair under the hat, she was judged in two moments. In the material world, Hester is like a cold, flesh-and-blood sculpture, but in the spiritual world, she is a completely different life. In essence, Hester lives in a spiritual space full of independent spirit, free thoughts, romantic feelings, and burning passion.

With regard to Dimmesdale, we first met him when Hester was punished at the penalty station. As the story evolved, it was discovered that Dimmesdale was always in the palm of his hand. He has become increasingly worried, and there are deep depression and troubles in his throat. He flashed his words and explained that if he confessed his sin, he would no longer be allowed to benefit mankind. The hypocritical Dimmesdale often watches in the secret room alone in the middle of the night to relieve the suffering of conscience. He sometimes whipped himself; sometimes hunger strikes; sometimes he carefully examined his face in front of a well-lit mirror. Because he couldn't stand his unknown sin, in the middle of the night of May, he climbed to the table and screamed loudly - almost wishing to be heard and discovered, thus freeing the pain. On the third appearance in the torture platform, Dimmesdale succumbed to courage and confessed happily, feeling that he had been forgiven by God. In fact, people can't see and feel the rich spiritual world of Dimmesdale. In the material space, the sacred, noble pastor, in essence, lives in a spiritual space full of serious elements such as sin, hypocrisy, repentance, and condemnation. In a sense, everything in the spiritual space is the most authentic and practical thing that a poor pastor needs to deal with.

Chillingworth' s debut is also in the material space centered on the torture platform. When he saw Hester's publicity on the torture platform because of adultery, he thought that he should personally investigate and crack the mystery of Hester's biological father. In the investigation, when he saw the bright red and unhealed scars on Dimmesdale' s chest, he was as ecstatic as Satan saw a fallen soul entering hell. Chillingworth' s work mainly concentrates on "analysis of a heart full of torture" (Hawthorne, 1983: p. 264), though he is not a real doctor, but a man who interested in the "alchemy" (Hawthorne, 1983: p. 179) who will recall us of the devil characters in Hawthorne' s romances including "The Haunted Quack" (1831), "The Birth-mark" (1843), and Dr. Grimshaw's Secret (1861, publishing in 1883), in which doctors usually own negative characters. It will also drive us back to the scene in prison where he meets Hester: 
"Drink, then," replied he, still with the same cold composure. "Dost thou know me so little, Hester Prynne? Are my purposes wont to be so shallow? Even if I imagine a scheme of vengeance, what could I do better for my object than to let thee live- than to give thee medicines against all harm and peril of life- so that this burning shame may still blaze upon thy bosom!" As he spoke, he laid his long forefinger on the scarlet letter, which forthwith seemed to scorch into Hester's breast, as if it had been red-hot. He noticed her involuntary gesture, and smiled." Live, therefore, and bear about thy doom with thee, in the eyes of men and women- in the eyes of him whom thou didst call thy husband- in the eyes of yonder child! And, that thou mayest live, take off this draught. $^{6}$ (Hawthorne, 1983: p.180)

Here, we can really link the figure of the character to the space he stays in, when the "cold" and "smile" form a dichotomy between the freeman (Chillingworth) and the prisoner (Hester), and also refer to the bifurcation between the inner space (prison) and the outer space (Boston). Chillingworth pursues comfort from this psychological anatomy, and gloated to the burning fire of the burning fire. He felt that he was destined to torture the pastor, and this destiny is attuned perfectly with the duty of the prison, to punish the prisoners for their sin cruelly. It will drive us to link this scene to the last time when we saw Roger Chillingworth, the third time he appears at the torture platform to try to stop Dimmesdale from publicly repenting. When Dimmesdale dies on the stage and repents, Chillingworth stumbles beside him, "with a blank, dull countenance, out of which the life seemed to have departed" (Hawthorne,1893: p. 338). The Avengers also dies less than a year after losing their life goals. It can be said that Chillingworth truly lives in his own spiritual world, which is full of hypocrisy, coldness, revenge, darkness, arrogance and punishment. Such a spiritual space is the space where Chillingworth really lives. In fact, Hawthorne has at least fabricates three different spiritual spaces. In these psychological spaces, through the appearance of discontinuous characters, Hawthorne forces readers to juxtapose different images of their characters in a moment. These spiritual spaces tell a complete story, if any space is extracted, The plot of the picture will be missing and the meaning will not be complete.

\section{Social space and the Forming of Personal Identities}

Lefebvre believes that social space is produced by society and also produces society. With regard to the intimate relationship between social space and social production, Lefebvre pointed out that on the one hand, every social space is produced in a certain social production mode, which is the result of a certain social process. The process intersects with meaningful and meaningless, cognitive and direct existence, practical and theoretical trends, so social space cannot be clearly divided into material or spiritual. On the other hand, space is also a place where all social forces, social conflicts, and all social forces are intertwined, and it is the "second nature" of society. Therefore, social space cannot be a static "platform" during the operation of social movements, and conversely it contains the infinite possibilities of change, or, in another word, "social space is what permits fresh actions to occur, while suggesting others and prohibiting yet others." (Lefebvre, 1991: p. 73)

At the beginning of The Scarlet Letter, Hawthorne uses the words "sad color" and "gray" to determine the dominant atmosphere of the story. The words "Boston", "Congel", "King's Church" also brought readers into the background of Boston and the early American Puritans. Hence, the identities of individuals in Boston were closely linked to their social space, and never unchained through the whole book. Due to the strong religious atmosphere in early England, the gloomy and dark atmosphere formed the characteristics of local customs and customs, and the novel was shrouded in a tragic color. But it is these invisible shadows and psychological contradictions caused by these regional regimes and churches that make this unique space constitute a powerful spiritual and cultural magnetic field that attracts and excludes the social relations of various characters. And become the internal basis of the narrative pattern of the novel. Hawthorne's design and arrangement of the plot is largely constrained by this "the politics of regional, national, and transnational landscapes through time." (Friedman,2005: p.198) From Hawthorne's description of the torture platform, we found that this material space centered on the torture platform is the social relationship at that time. Members of the Boston theocracy government, including "the Governor, and several of his counsellors, a judge, a general, and ministers of the town; all of whom sat or stood in a balcony of the meeting-house, looking down upon the platform." (Hawthorne, 1983: p. 166). Hawthorne puts the pastor and the judge on the balcony at the same time is intended to point out that in the country of theocracy (the country that God dominates), the state is the arm of the church and is responsible for enforcing the decree. From this we deeply understand the true beliefs of the Puritans. It is the decentralization of the church and the state, and the power of the theocratic politics of the Puritans in Boston is further emphasized. This is based on the social order promoted by the Old Testament, that is, the Puritan's theocracy has a law and order in the country and the church to maintain colonial law. Under the condition of equal responsibility, it is always the background of the story "Scarlet letter".

In addition, the meaning of space in literature is much more subtle and complicated than the meaning of place and scene. The first stage of the prison appeared at noon, and Hester was under strong sunlight and public eyes. Accept the

\footnotetext{
${ }^{6}$ The Italic is added when citing.
} 
punishment of the Puritan society. The second time in the dark, the scene of Dimmesdale and Hester and Pearl holding hands is not seen at night, which is also the hidden sin of the pastor. The third time appeared in the daytime, everyone can see the confession of Dimmesdale on the platform in broad daylight. We noticed that in this space, the characters are developing, the plot is changing, and taking care of the moral meaning of light and darkness - the light of the day reveals sin, while the darkness hides sin and cowardice. ${ }^{7}$ Thus, Hawthorne's literary description of the torture platform can not only reveal how space is organized, but also reveal how space is defined by social behavior. After leaving the prison and the prison, Hester took the child and settled in a deserted seaside lodge. The home is a place that gives people a place to live and be safe; but the home is a kind of imprisonment for Hester, separating her from the crowd. In the face of the Puritan precepts and long-term loneliness, Hester can only be forced to endure the contempt of her audience, piously implement her good deeds, and use her spiritual space to fight against the material space to win the peace of mind. In the face of the Puritan precepts and his hypocritical heart, Dimmesdale can only torture himself in his spiritual space, comfort himself, and eventually force himself to confess sin, even lose his life and find the peace of conscience. Faced with the shame of a malformed marriage and the wife's adultery, Roger Chillingworth chose to go to the road of revenge, fell into the abyss of sin, suffered the evil of appearance due to mental deformity, and after losing the direction of life. Looking back at Hawthorne's spiritual space for Hester, Dimmesdale and Chillingworth, they all promote the story.

If personal portraits and psychological excavations provide a pole for space, social images provide another dimension of the spatial form of The Scarlet Letter. The social picture here refers to the social and cultural space composed of religious rituals, festival rituals, carnivals and parades with the physical space of the square as the carrier. In the previous 20 chapters, "Scarlet letter" connects the psychology and space of the characters through the presentation of the prison, the market, the lodge, the governor's hall, and the space of the forest, and powerfully portrays the three-dimensional characters through the multiple meanings of the space. Excavate the complex and diverse psychological reality of the characters. But the above space is mainly for individual character activities. In the last three chapters of the novel, the author changed the narrative technique and used a wide-angle lens to collectively bring together all the characters in the story through the market "New England Festival". The description of "and the parade" shows the readers a broad social and cultural space. The "market" in the novel is similar to the square in the modern sense. It is a part of the urban public space. It is a place to record important historical events and leave a collective memory. The ceremonial celebrations such as religions and festivals held in the market are Public time, space and unique behavior constitute a special cultural space. The public physical space of the market is not only a container of life, but also an open place where different life experiences and different values communicate and collide. It is an extremely vital part of urban culture. Here, traditional culture, ethics, religious consciousness, regional customs, humanity and the activities and carnivals of people in a specific environment constitute the cultural space in the narrative. In the market culture space composed of festivals and religious sermons, Hawthorne brings together all the characters in the story, people of different ages, genders, occupations, status, such as blacksmiths, jailers, governors, pastors, witches, Soldiers, residents, sailors who sailed across the ocean, and Indians in the forest all appeared on the festival market. There is a rare "excessive happiness" on the faces of the people. Puritans concentrated all the joys allowed by people's weaknesses and the joy of the public on this bliss day of the year.

However, we cannot think arbitrarily that the social space in The Scarlet Letter has only the simplex meaning. On the other hand, the social space should be seen as a complex synthesis, so heterotopology becomes a way of looking at and interpreting all spaces and their consequential effects." (Soja, 2010: p.104) It gives us chance to analyze the complex social space represented intensely in the following scene depicted by Hawthorne:

Had there been a Baptist among the crowd of Puritans, he might have seen in this beautiful woman, so picturesque in her attire and mien, and with the infant at her bosom, an object to remind him of the image of Divine Maternity, which so many illustrious painters have viewed with one another to represent; something which should remind him, indeed, but only by contrast, of that sacred image of sinless motherhood, whose infant was to redeem the world. (Hawthorne, 1983: p.166)

In the narrow space described above, the whole world falls into a kind of prevailed happiness. However, we cannot neglect the influence behind the social space. Since New England residents inherited the legacy of the British ancestors, especially those early Puritans, it created a link between the Puritan American and the England, even without any direct link. However, this coherence scene in the space can also remind us the Carnivalesque Scene in Hawthorne's works, which usually represents the potential emergency behind the joyful scene. It is true that all people celebrate a certain civic activity with bonfires, feasts, performances, and parades, combining joyful recreation with solemnity, but when we consider the fate of Hester Prynne through the whole work, this joyful social space is full of crisis, the inexorability of Puritans and the rigor moral discipline they inherit from their England father, beneath the joyful scene. Therefore,

\footnotetext{
${ }^{7}$ Cf. Colacurcio, Michael J. "Introduction" in Colacurcio, Michael J. ed. New Essays on "The Scarlet Letter". Cambridge: Cambridge University Press, 1985
} 
Hawthorne provide a well-rounded system to treat the social space in a heterogeneous frame: the New England social space is not only a ramification from the social space of England, but also an isolated space with its own social contradictories.

The hard and simple life of the religion that must be practiced on weekdays has somewhat eased in this festival with public ceremonies. Everyone wears the best clothes to the market, and the noble costumes of political officials and socialists reflect the old style. There are melancholic grays, browns and blacks of British immigrants on the market, but there are also a variety of eye-catching colors and dresses: Indians with brightly colored moose robes, comics like Mrs. Sibbs Magnificent, the parade in the glorious costumes, the gorgeous robes of the governors and law enforcement officers, and the colored clothes of the sailors. Hawthorne's meticulous portrayal of backgrounds, characters, and behaviors, the appearance of clothing and external appearances of various characters make this scene look like a movie or a Broadway theater scene. In addition to the external descriptions of various characters, Hawthorne also described some unique public activities, such as friendship games with sticks, fencing competitions, performances, and evangelistic speeches as the climax of the day.

The paintings of the Puritan period, on the one hand, express the inheritance of the colonies of the New World to the legacy and cultural traditions of the Old World; on the other hand, it also reflects the atmosphere and activities of this festival with carnival nature. A very different state of teaching everyday life. The French sociologist Durkheim once regarded the festival as a collective overdoing. At the same time, the festival, especially the Christian festival, should be seen as a human development under the influence of local causes, which means that festivals are always accompanied with the local social space. This theme is also well developed in Hawthorne's work "The May-Pole of Merry Mount" ${ }^{8}$, which is also taken by Durkheim as a typical symbol of the local festival. He builds a social space of novels through the combination of image space and spiritual space. The first level of social space is the specific social environment of the character's activities, which can be called a small space. In the imagery movement of novel creation, he specifically shows the conflict of interpersonal relationships, which constitutes the scene of the plot. He plays a direct role in the formation of the character and the state of the plot development. The second level is the historical background. It stipulates and limits the movement of the image of the character in what kind of society, and it is the sum of social relations within a certain period of time. It can be called a large space. Large spaces determine and restrict small spaces, and small spaces reflect and imply large spaces. The space in human society is no longer a purely natural space. Although natural space is still the source of social processes and will not completely die out, it is social space that now dominates human life. It can be said that through the actions of the characters on the two levels of the novel, Hawthorne is revealing the essence of Boston's time and space, revealing the social production and social relations at that time, and making us form an overall impression of American society.

\section{Conclusion}

In Lefebvre's view, space is not only the existence of matter, but also the existence of form, and a container of social relations. Space has its material properties, but it is by no means a material existence that has nothing to do with humans, human practice, and social relations. Conversely, because people are involved, space can only make sense to us. Space also has its spiritual attributes, as we are familiar with the concepts of social space, national space, daily life space, urban space, economic space, political space, but this does not mean that the conceptual and social significance of space can be erased or Replace it as an objective existence of geographical space. So space is neither an object nor a subject.

Space can not only create a place for the story of the novel, but also create a situation and convey the image. At the same time, space itself not only accommodates various social relationships, but is also a powerful and dynamic variable. As the space changes dynamically, the atmosphere of the story and the image expressed by the author also change. In this respect, the space of the novel has special significance for expressing the theme of the novel and conveying the image. It is through the construction of space that Hawthorne combines serious moral and historical content with excellent artistic expressions, and combines the imagination of talent with superb language skills to show us his personality and creativity, thence to give The Scarlet Letter a strong vitality and enduring charm.

At the same time, beyond the purified object, the space in The Scarlet Letter bridges the gap between the objective world and the subjectivity, and creates a unified totality which contains the characters and the space. It is through the construction of space that the theme and meaning of the human spiritual ecological crisis in the novel is better manifested. The characters in self-interest, hypocrisy and indifference in the story are the true portrayal of interpersonal relationships. In such a social environment, people's inner feelings are lonely, and people's lifestyles and values have undergone tremendous changes. The human spiritual ecology is in crisis, and the good nature of kindness and tolerance is stifled,

\footnotetext{
${ }^{8}$ Cf. Colacurecio, Michel J (1995) The Province of Piety: Moral History in Hawthorne' s Early Tales. Durham\& London: Duke Univ. Press \& Dekker, George (1987). The American Historical Romance. New York: Cambridge Univ. Press.
} 
which leads to serious loss of mind. Both of the conditions of individuals fit quite well with the spirit of the space in the context of the story. It is in this sense that The Scarlet Letter shows Hawthorne's contemplation and transcendence of the real world. Hawthorne's space in the novel is not simply juxtaposed, but intervening, intermingling, superimposing each other, and sometimes even contradicting each other. When we think about the space that Hawthorne constructs, we should realize that whether it is material, spiritual, or social, it should be regarded as both real and imaginary, both concrete and abstract, both existential and metaphorical.

\section{References}

Darby, H. C. (1948). The Regional Geography of Thomas Hardy's Wessex. Geography Review, 38(3), 426-443.

Dolis, J. (1993). The Style of Hawthorne's Gaze: Regarding Subjectivity. Tuscaloosa\& London: University of Alabama Press.

Durkheim, É. F., \& Karen, E. (1981). The elementary forms of religious life. New York: The Free Press.

Fernie, D. (2011). Hawthorne, Sculpture, and the Question of American Art. Farnham: Ashgate Publishing.

Foucault, M. (1986). Of Other Spaces. Diacritics, 16(1), Spring, 22-27.

Friedman, Susan in Phelan, James \& Rabinowitz, Peter J. ed. (2005). A Companion to Narrative Theory. London: Wiley-Blackwell.

Goonewardena, K. et. al ed. (2008). Space, difference, everyday life: reading Henri Lefebvre. New York: Routledge. https://doi.org/10.4324/9780203933213

Hawthorne, N. (1982). Nathaniel Hawthorne: Tales and Sketches. New York: The Library of America.

Hawthorne, N. (1983). Nathaniel Hawthorne: Collected Novels. New York: The Library of America.

Lefebvre, H. (1991). The Production of Space. London: Wiley-Blackwell.

Michael, C. (1986). New Essays on The Scarlet Letter. Cambridge University Press.

Soja, E. W. (1996). Third-space: Journeys to Los Angeles and Other Real-and-Imagined Places. Oxford: Basil Blackwell.

Soja, E. W. (2009). In Warf, Barney \&Arias, Santa ed. (2009). The spatial turn: interdisciplinary perspectives. London: Routledge.

Soja, E. W. (2010). Seeking spatial justice. Minneapolis: University of Minnesota Press.

Tuan, Y. F. (1977). Space and Place The Perspective of Experience. Minneapolis: University of Minnesota Press.

Warf, B., \&Arias, S. In Warf, Barney \&Arias, Santa ed. (2009). The spatial turn: interdisciplinary perspectives. London: Routledge.

\section{Copyrights}

Copyright for this article is retained by the author(s), with first publication rights granted to the journal.

This is an open-access article distributed under the terms and conditions of the Creative Commons Attribution license which permits unrestricted use, distribution, and reproduction in any medium, provided the original work is properly cited. 